\title{
Awareness and Level of Knowledge in Preventing Coronary Heart Disease Among Community Sample
}

\author{
Ni Kadek Ayu Suarningsih ${ }^{1}$, I Made Suindrayasa ${ }^{2}$ \\ Nursing Study Program \\ Faculty of Medicine-Udayana University \\ Jimbaran \\ ayu.suarningsih@gmail.com \\ Nursing Study Program \\ Faculty of Medicine-Udayana University \\ Jimbaran
}

\begin{abstract}
CHD is ranked number one as a cause of death in non-communicable diseases in Indonesia. The increasing number of people with CHD not only having an impact on mortality rates also an increase in health care needs. Adequate knowledge of the disease contributes to an accurate understanding of the disease and improves adherence to a healthy lifestyle to prevent CHD. This study aims to analyze the awareness and level of community knowledge in preventing CHD. This research was a quantitative research with descriptive analytic method. Awareness and level of knowledge about CHD were evaluated using The Heart Disease Fact Questionnaire. In this study, a total of 60 respondents were obtained through a Cluster Random Sampling in the population of people who have not been diagnosed with CHD in the Village of Timpag, Tabanan Regency, Bali. The main results of this study indicated that awareness and knowledge of the highest risk factors are smoking $(89.1 \%)$ followed by a factor of high cholesterol (86.6\%) and high LDL cholesterol levels (86.3\%) and uncontrolled blood pressure (85.9\%) and overweight (82.4\%). Conversely, risk factors for diabetes (50.7\%), HDL cholesterol levels (52.1\%), and physical activity (53.5\%) received less attention. This study found that the majority of respondents were aware of and have adequate knowledge about CHD risk factors. The results of this study can add information in the development of health promotion materials or policies as an effort to prevent CHD. Further research with a larger population needs to be done to increase public awareness of CHD.
\end{abstract}

\section{Index Terms - Awareness, Coronary Heart Disease, Level of Knowledge}

\section{INTRODUCTION}

Coronary Heart Disease (CHD) is a cardiovascular disease that has a high mortality rate in various countries. The Centers for Disease Control and Prevention (CDC) has reported that heart disease is the main cause among 15 causes of death in the United States [1]. Changes in lifestyle today are shifting from infectious diseases and are prone to nutrition to degenerative diseases, such as heart disease and blood vessels that cause sudden death. Based on data from the World Health Organization (2014), CHD is the number one cause of death compared to other non-communicable diseases in Indonesia [2].

The increase in the number of CHD sufferers from year to year is due to lack of public knowledge about risk factors for coronary heart disease and lack of efforts in preventing this disease. The main factor suspected to be a predictor of increasing CHD morbidity and mortality is the inability of the community to prevent CHD risk factors[3]. These factors include male sex, increasing age, family history, high cholesterol, smoking, diabetes, hypertension, obesity, 
psychosocial factors, and alcohol consumption, low consumption of fruit and vegetables, and physical inactivity [4].

Some clinical guidelines recommend lifestyle modification for the prevention and treatment of heart disease including complete smoking cessation, blood pressure control, lipid management, physical activity, weight management, management of type two diabetes mellitus, treatment and rehabilitation of the heart [5,6]. In addition, having adequate knowledge about CHD through health education is believed to be an important requirement for adherence to a healthy lifestyle $[7,8]$ in the prevention of CHD. Disease knowledge contributes to an accurate understanding of disease and increases adherence to a healthy lifestyle to prevent CHD. As a result, having knowledge about the disease can help inhibit the disease process [9]. Furthermore, prevention must be tried as much as possible by controlling the risk factors for CHD both primary and secondary.

Primary prevention is the best effort to reduce the number of people with CHD. Although health services have tried to promote early prevention of CHD, patients often come to hospitals or other health facilities that are already in bad condition, late given treatment, or even have died. So that this promotion has not run optimally. This study aimed to analyze the awareness and level of knowledge of individuals in preventing coronary heart disease.

\section{METHOD}

This research was a quantitative research with descriptive analytic method. In this study, respondents were obtained through a Cluster Random Sampling in the population of people who have not been diagnosed with CHD in the Village of Timpag, Tabanan Regency, Bali.

Awareness and level of knowledge about CHD were evaluated using The Indonesian Version of the Heart Disease Fact Questionnaire [10]. The questionnaire consisted of 15 questions that were developed to evaluate knowledge about the main factors that cause CHD. The total knowledge score is calculated by the total number of correct responses, with a range of 0 to 15 , and a higher score indicates greater knowledge.

Univariate analysis was used in presenting data of respondents' characteristics while Chi Square test was used to analyze the relationship of family history of heart disease with awareness and level of knowledge.

\section{RESULT}

\section{A. Demographic Characteristic}

This study involved 284 respondents in which the majority of respondents aged 46-65 years, amounting to $44.7 \%$, while the majority of respondents were female at $53.9 \%$. In this study $86.6 \%$ of respondents were married and only $3.2 \%$ had never attended school. Most respondents were farmers (42.6\%). In addition, $64.1 \%$ of respondents have a family history of heart disease.

\section{B. Awareness and Level of Knowledge in preventing CHD}

Table 1 showed the awareness and level of knowledge in the prevention of CHD. Awareness and knowledge of the highest risk factors are smoking $(89.1 \%)$ followed by a factor of high cholesterol (86.6\%) and high LDL cholesterol levels (86.3\%) and uncontrolled blood pressure (85.9\%) and overweight $(82.4 \%)$. In contrast, only risk factors for diabetes (50.7\%), HDL cholesterol levels (52.1\%), and physical activity (53.5\%) were not given enough attention that these factors were risk factors for CHD.

Table 1 Awareness and Level of Knowledge in preventing CHD

\begin{tabular}{lll}
\hline \multicolumn{1}{c}{ HDFQ Questionnaires } & $\begin{array}{l}\text { True } \\
(\%)\end{array}$ & $\begin{array}{l}\text { False } \\
(\%)\end{array}$ \\
\hline $\begin{array}{l}\text { A person always knows when they have heart } \\
\text { disease }\end{array}$ & 64.1 & 35.9 \\
\hline $\begin{array}{l}\text { If you have a family history of heart disease you } \\
\text { are at risk for developing heart disease }\end{array}$ & 64.8 & 35.2 \\
\hline $\begin{array}{l}\text { The older a person is, the greater their risk of } \\
\text { having heart disease }\end{array}$ & 66.5 & 33.5 \\
\hline \begin{tabular}{l} 
Smoking is a risk factor for heart disease \\
\hline $\begin{array}{l}\text { High blood pressure is a risk factor for heart } \\
\text { disease }\end{array}$
\end{tabular} & 83.1 & 16.9 \\
\hline $\begin{array}{l}\text { Keeping blood pressure under control will reduce } \\
\text { a person's risk for developing heart disease }\end{array}$ & 85.9 & 14.1 \\
\hline $\begin{array}{l}\text { High cholesterol is a risk factor for developing } \\
\text { heart disease }\end{array}$ & 86.6 & 13.4 \\
\hline $\begin{array}{l}\text { Eating fatty foods does not affect blood } \\
\text { cholesterol levels }\end{array}$ & 75.7 & 24.3 \\
\hline $\begin{array}{l}\text { If your "good" cholesterol (HDL) is high you are } \\
\text { at risk for heart disease }\end{array}$ & 52.1 & 47.9 \\
\hline $\begin{array}{l}\text { If your "bad" cholesterol (LDL) is high you are at } \\
\text { risk factor for heart disease }\end{array}$ & 86.3 & 13.7 \\
\hline $\begin{array}{l}\text { Being overweight increases a person's risk for } \\
\text { heart disease. }\end{array}$ & 82.4 & 17.6 \\
\hline $\begin{array}{l}\text { Regular physical activity will lower a person's } \\
\text { chance of getting heart disease }\end{array}$ & 53.5 & 46.5 \\
\hline $\begin{array}{l}\text { Diabetes is a risk factor for developing heart } \\
\text { disease }\end{array}$ & 50.7 & 49.3 \\
\hline \begin{tabular}{l} 
High blood sugar puts a strain on the heart \\
\hline
\end{tabular} & 79.2 & 20.8 \\
\hline
\end{tabular}

Table 2 Total score of Awareness and Knowledge Level of Respondents in preventing $C H D(N=284)$

\begin{tabular}{lcccc}
$\begin{array}{c}\text { Awareness and } \\
\text { Level of Knowledge }\end{array}$ & $f$ & $\%$ & $M$ & $S D$ \\
\cline { 1 - 3 } Good & 127 & 44.7 & & \\
\cline { 1 - 3 } Average & 109 & 38.4 & & 17.4 \\
\cline { 1 - 3 } Poor & 48 & 16.9 & & \\
\hline
\end{tabular}

Table 2 shows an average total score of $72.3 \%$ of the $100 \%$ maximum score of which $44.7 \%$ have good awareness and knowledge of CHD risk factors, while 
only $16.9 \%$ have less awareness and knowledge of risk factors in preventing CHD. Based on the results of statistic with chi square test showed statistically there is no relationship between family history of respondents who have heart disease and awareness and level of knowledge of CHD was $(p=0.688$, > $0.05)$.

\section{DISCUSSION}

Heart disease is increasingly common with the aging process. Knowledge of heart disease and its risk factors is a vital requirement for changing individual behavior, physical condition and daily life practices [11]. To obtain good outcomes, it is necessary to improve individual knowledge about heart disease [12]. Individuals must be aware of the implications of heart disease, risk factors, and symptoms to enable individuals to be proactive in reducing the risk of heart disease [13].

Based on this this study, most of respondents have good knowledge about CHD (44.7\%), respondents may not be aware of the specific actions needed to reduce CHD risk. Awareness and knowledge of risk factors that are commonly known by respondents in this study are smoking (89.1\%) followed by high cholesterol levels $(86.6 \%)$ and high LDL cholesterol levels $(86.3 \%)$, and uncontrolled blood pressure $(85.9 \%)$, and overweight $(82.4 \%)$. These results are in accordance with previous studies where awareness and level of knowledge on smoking risk factors received attention above $83 \%$ of all risk factors [14].

Family history is an independent risk factor for heart disease which has the potential to be a screening tool to identify people, especially young adults without symptoms, who are at high risk of developing CHD [15]. In this study all respondents had never been diagnosed with CHD but more than half (64.1\%) had a family history of heart disease. Nonetheless, this study shows there is no relationship between family history of heart disease with awareness and level of knowledge of respondents in preventing CHD ( $p>0.05$ ). Previous studies suggest a person's awareness of a family history of heart disease or the risk of heart disease in oneself is not an adequate predictor of changes in behavior related to the health of the individual [16].

Respondents in this study were mostly in the age range 46-65 years. According to the 2012 NHLBI, men and women have an increased risk of heart disease when they reach middle age (45 to 55 years).
Only risk factors for Diabetes (50.7\%), HDL cholesterol levels (52.1\%), and physical activity $(53.5 \%)$ were not given much attention in this study. There is no single risk factor that is responsible for heart disease. For this reason, strategies to reduce risk factors or their severity are very important. Primary prevention programs that focus on diet, exercise, and the dangers of heart disease must be emphasized. Lifestyle changes such as modifying dietary habits can benefit those who are at risk of developing risk factors. Lifestyle changes such as engaging in active lifestyles must be emphasized. Education about the benefits of sports is important and finding fun and sustainable activities is important. Fun and motivational training programs have been proven to increase training participation and sustainability [17]. Media involvement can be very helpful in conveying these messages specifically to the public. With regard to individuals who smoke, referrals to smoking cessation programs and medications such as the use of nicotine replacement therapy [18] can be considered to help with quitting smoking.

\section{CONCLUSION}

This study found that the majority of respondents were aware of and have adequate knowledge about CHD risk factors. The results of this study can add information in the development of health promotion materials or policies as an effort to prevent CHD. Further research with a larger population needs to be done to increase public awareness of CHD.

\section{ACKNOWLEDGMENT}

The Author would like to acknowledge financial support for this study in the form of grants Non-Tax State Revenue (PNBP) from Udayana University, Bali.

\section{REFERENCES}

[1] Murphy SL, Xu JQ, Kochanek KD., "National Vital Statistics Reports", 2010.

[2] World Health Organization, "Indonesia: Non-communicable Diseases (NCD) Country Profile", 2014. Available from: http://www.who.int/nmh/countries/idn_en.pdf

[3] Indrawati L., "Relationship Between Knowledge, Attitude, Perception, Motivation, Family Support And Information Sources of Patients with Coronary Heart Disease with Secondary Prevention Measures of Risk Factors.”, 2014.

[4] American Heart Association, "Blood Pressure vs. Heart Rate." 2014. Available from: http://www.heart.org/HEARTORG/Conditions/HighBloodPressure/A boutHighBloodPressure/Blood-Pressure-vs-HeartRate_UCM_301804_Article.jsp\#.VkB0Bp6qqko 
[5] Pereira R.F., Franz M.J., "Prevention and treatment of cardiovascular disease in people with diabetes through lifestyle modification: Current evidencebased recommendations. Diabetes Spectrum." 2008.

[6] Smith S., Benjamin E.J., Bonow R.O., Braun L.T., Creager M.A., Franklin B.A., Taubert K.A., "AHA/ACCF Secondary prevention and risk reduction therapy for patients with coronary and other atherosclerotic vascular disease: 2011 update a guideline from the American Heart Association and American College of Cardiology Foundation. Circulation.", 2011.

[7] Bellman C., Hambraeus K., Lindback J., Lindahl B., "Achievement of secondary preventive goals after acute myocardial infarction: A comparison between participants and nonparticipants in a routine patient education program in Sweden." Journal of Cardiovascular Nursing, 2009.

[8] Dona E., Susan E., Zachary M., Irvine J., Sherry L., "Gender differences in health information needs and decisional preferences in patients recovering from an acute ischemic coronary event", Psychosomatic Medicine, 2004.

[9] Mosca L., Greenberger H.M., Dolor R.J., Newby K., \& Robb, K.J., "National study of women's awareness, preventive action, and barriers to cardiovascular health", Circulation, 2006.

[10] Wagner J., Lacey K., Chyun D., Abbott G., "Development of a questionnaire to measure heart disease risk knowledge in people with diabetes: the Heart Disease Fact Questionnaire. Patient Education and Counseling", 2005.

[11] Zeljko R., Zdenko S., "The Perception and Knowledge of Cardiovascular Risk factors among Medical Students", Croat Med J, 2012.

[12] Thomas S.M.D., Anna Y.S., Paul D., "Study on Cardiovascular Disease in an Urban Health Centre of Kolkata", Indian Journal of Community Medicine, 2008.

[13] Lori M., Anjanette F., Rosalind F., Rose M.R., "Tracking Women's Awareness of Heart Disease An American Heart Association National Study", Circulation, 2004.

[14] Mendis, Shanthi, Puska, Pekka, Norrving B., "Global Atlas on Cardiovascular Disease Prevention and Control", 2011.

[15] Valdez R., Greenlund K.J., Khoury M.J., Yoon P.W., "Is family history a useful tool for detecting children at risk for diabetes and cardiovascular diseases?", A public health perspective, Pediatrics, 2007.

[16] Imes C.C., Lewis F.M., "Family history of cardiovascular disease, perceived cardiovascular disease risk, and health-related behavior: a review of the literature", The Journal of cardiovascular nursing, 2014.

[17] Alpert P.T., "Alternative exercise may be attractive to more individuals", Home Health Care Manag Pract, 2010. Available from: http://dx.doi.org/10.1177/1084822309357006

[18] Centers for Disease Control and Prevention., "Quitting smoking among adults-United States, 2001-2010”, 2011. Available from: http://www.cdc.gov/tobacco/data statistics/mmwrs/byyear/2011/mm 6044a2/intro.htm. 